\title{
Maternal Mortality
}

National Cancer Institute

\section{Source}

National Cancer Institute. Maternal Mortality. NCI Thesaurus. Code C111860.

The death of a woman while pregnant or within 42 days of the end of the pregnancy, irrespective of the duration or anatomic site of the pregnancy, due to any cause related to or aggravated by the pregnancy or its management, but not from accidental or incidental causes. 